$12-4-2009$

\title{
Using Literary Ethnography as a Form of Qualitative Document Synthesis to Explore the Maltreatment of Vulnerable Populations: An Examination of Verbal Neglect and Abuse in Nursing Homes
}

Jason S. Ulsperger

Arkansas Tech University, julsperger@atu.edu

Follow this and additional works at: https://nsuworks.nova.edu/tqr

Part of the Quantitative, Qualitative, Comparative, and Historical Methodologies Commons, and the Social Statistics Commons

\section{Recommended APA Citation}

Ulsperger, J. S. (2009). Using Literary Ethnography as a Form of Qualitative Document Synthesis to Explore the Maltreatment of Vulnerable Populations: An Examination of Verbal Neglect and Abuse in Nursing Homes. The Qualitative Report, 14(4), 806-823. https://doi.org/10.46743/2160-3715/2009.1379 


\title{
Qualitative Research Graduate Certificate
}

业焦

NSU

\author{
Exclusively Online $\bullet 18$ Credits
}

\section{Using Literary Ethnography as a Form of Qualitative Document Synthesis to Explore the Maltreatment of Vulnerable Populations: An Examination of Verbal Neglect and Abuse in Nursing Homes}

\begin{abstract}
Studying vulnerable populations can be highly problematic. This is especially true when they are located in institutional settings. When gatekeepers block access and a researcher wants to examine a delicate topic, one ethical, feasible way to paint an interpretive picture of everyday life involves the use of a literary ethnography. With data on the verbal neglect and abuse of elders in United States nursing homes, this paper details the six-stages of a literary ethnography. It includes a discussion of identifying sources, reading and interpreting the documents, identifying textual themes, classifying themes, developing a set of analytic constructs, and re-reading documents for contextual confirmation. It concludes with a discussion of literary ethnography weaknesses and directions for future applications.
\end{abstract}

\section{Keywords}

Vulnerable Populations, Literary Ethnography, and Nursing Home Abuse

\section{Creative Commons License}

\section{c) (i) (2)}

This work is licensed under a Creative Commons Attribution-Noncommercial-Share Alike 4.0 License. 


\title{
Using Literary Ethnography as a Form of Qualitative Document Synthesis to Explore the Maltreatment of Vulnerable Populations: An Examination of Verbal Neglect and Abuse in Nursing Homes
}

\author{
Jason S. Ulsperger \\ Arkansas Tech University, Russellville, Arkansas, USA
}

\begin{abstract}
Studying vulnerable populations can be highly problematic. This is especially true when they are located in institutional settings. When gatekeepers block access and a researcher wants to examine a delicate topic, one ethical, feasible way to paint an interpretive picture of everyday life involves the use of a literary ethnography. With data on the verbal neglect and abuse of elders in United States nursing homes, this paper details the six-stages of a literary ethnography. It includes a discussion of identifying sources, reading and interpreting the documents, identifying textual themes, classifying themes, developing a set of analytic constructs, and re-reading documents for contextual confirmation. It concludes with a discussion of literary ethnography weaknesses and directions for future applications. Key Words: Vulnerable Populations, Literary Ethnography, and Nursing Home Abuse
\end{abstract}

\section{Introduction}

A vulnerable population is a group of people a researcher wants to study that has limited resources and is at risk for encountering a lowered level of health status (Flaskerud \& Winslow, 1998). Accessing and examining the social worlds of certain vulnerable populations such as nursing home residents can be highly problematic. This is especially true when they are located in institutional settings with agents of control skeptical of researchers from the outside coming in and observing behavior. When gatekeepers block access and a researcher wants to examine a delicate topic, one ethical, highly feasible way to paint an interpretive picture of everyday life for vulnerable populations involves the use of a literary ethnography.

Family members care for a majority of older Americans. However, the United States does have nearly 1.5 million of its population aged 65 and over in nursing homes. Oftentimes, residents in these facilities have a temporary term of stay. Nearly $33 \%$ of elderly men and $50 \%$ of older women spend at least some time in a nursing home before they die. This type of resident is typically there to recover from a temporary health problem. Others, such as those with serious physical or mental debilitations, stay for longer periods. Many of these residents are 85 years of age or older (Statistical Abstract of the United States, 2007).

U.S. nursing homes are notoriously associated with stories of neglect and abuse (see DeFrancis, 2002; Pear, 2002, p. 11). Using results from a study of nursing homes, 
this paper uses structural ritualization theory to look at verbal neglect and abuse in longterm care facilities with literary ethnography techniques. This paper focuses on two main research questions. What types of verbal neglect and abuse exist in nursing homes? What are some of the causes of verbal abuse and neglect in nursing homes? Though these questions guide this work, one of the paper's main goals is to help readers understand how they can use a literary ethnography to study vulnerable populations and controversial topics like nursing home abuse and neglect.

\section{Theoretical Underpinnings}

This research uses a sociological perspective known as structural ritualization theory (SRT). SRT views ritualized symbolic practices (RSPs) as an essential aspect of social interaction. RSPs are stable actions that shape people's thought patterns and structure social environments. Therefore, RSPs involve repetitive actions that take on and express symbolic meaning (Knottnerus, 1997).

Four factors involving RSPs play a part in facilitating social structure repetitiveness, salience, homologousness, and resources. Repetitiveness involves the number of times people perform RSPs in a specific milieu. Salience involves whether or not actors in a designated environment view a RSP as highly important. Homologousness relates to the similarity between actions and symbolic meaning. It is possible that different RSPs in a social setting are similar in meaning and reinforce each other. For example, a college professor might lock the door when class starts every day so late students cannot enter the room. The same professor might ramble at the end of every lecture in order to keep students in class until their official time of release. These two rituals are different forms of behavior, but symbolically similar because they reinforce the professor's authority over students. Resources include any material or nonmaterial means actors need to participate in RSPs (e.g., money or knowledge). With the theory, rank is also a prominent concept. An identified RSP ranks above others when, based on the previously mentioned factors, it is repeated often, is visible, is similar to other RSPs, and people have the necessary resources to engage in it. The higher the rank of the RSP, the more likely it will shape people's cognitive frameworks and set the tone for behavior in a specific context (Knottnerus, 1997).

Many studies support SRT. They include research on 19th century French elite schools (Knottnerus \& Van de Poel-Knottnerus, 1999; Van de Poel-Knottnerus \& Knottnerus, 2002), slave societies (Knottnerus, 1999), experimental task groups (Sell, Knottnerus, Ellison, \& Mundt, 2000), an ancient militaristic social system (Knottnerus \& Berry, 2002), golf (Varner \& Knottnerus, 2002), Chinese American ethnic groups (Guan \& Knottnerus, 1999), and organizational deviance (Knottnerus, Ulsperger, Cummins, \& Osteen, 2006).

\section{Literary Ethnographies and Vulnerable Population Research}

In the area of content analysis, there is a tradition of using literary records to analyze social realities (see Allport, 1942; Denzin, 1978; Glassner \& Corzine, 1982; Thomas \& Znaniecki, 1918; White, 1986). Some call the systematic analysis of literary records narrative analysis (Manning \& Cullum-Swan, 1994). Others call it document 
analysis or narratology (Bailey, 1978; Marshall \& Rossman, 1995). Analysts in qualitative organizational studies use the term template analysis (King, 1998). Regardless, they all directly argue that the ethnographic study of literature is a suitable research method. Commentary on ethnographic methodology argues that the interpretation of literary evidence, as found in biographies, autobiographies, and research monographs, yields plentiful data for qualitative analysis because it provides valid themes for studying actor experiences (Denzin \& Lincoln, 2008).

Similar to a content analysis, literary ethnographies are useful for four specific types of research problems. First, they are helpful when the researcher needs to deal with a large volume of text. Second, they are beneficial when a researcher needs to ethically study a topic at a great distance. In other words, techniques involving literature analysis allow researchers to tap into the taken-for-granted social worlds of vulnerable populations that are not easy to survey or observe in restricted settings. Third, they allow researchers to analyze behavior, possibly deviant, that most people would not feel comfortable discussing face-to-face. Finally, literary ethnographies have the ability to unearth messages in documents that are hard to see with casual observation (Hodder, 1994).

A literary ethnography is similar to a meta-analysis. A meta-analysis combines findings from a wide range of studies to create a streamlined account of a topic. As opposed to a literary ethnography, a meta-analysis uses quantitative techniques to produce statistical evidence (Singleton \& Straits, 2005). A literary ethnography is also similar to a form of qualitative document synthesis known as meta-ethnography. Like a meta-analysis, a meta-ethnography analyzes a variety of previous studies to explore a research topic, but the studies tend to be exclusively qualitative (Noblit \& Hare, 1988). A literary ethnography uses previous qualitative research, but the sources do not all have to be research driven. They can include and actually encourage the use of text that does not orient itself to a research paradigm, such as the previously mentioned biographies and autobiographies (Van de Poel-Knottnerus \& Knottnerus, 1994) and ethnographic accounts (Hodges \& Ulsperger, 2005; Ulsperger \& Knottnerus, 2008). Moreover, a metaethnography tends to start with a set of documents that focus on a narrow issue. A literary ethnography does not. For example, if this research were a meta-ethnography, it might just focus on previous ethnographic works exclusively devoted to nursing home abuse and neglect. However, a majority of the sources used focus on nursing home life in general, thus creating the necessity for the researcher to extract out concepts and themes relating to abuse and neglect to generate a holistic picture of the phenomenon. With these points in mind, you do not have to view a literary ethnography as something entirely separate from a meta-ethnography. You should view it as a branch of meta-ethnography that provides unique, detailed stages for carrying out qualitative synthesis research (for details on the strengths and weaknesses of meta-ethnography, see Doyle, 2003).

This section uses Van de Poel-Knottnerus and Knottnerus' (1994) ideas, and some of the author's own, to detail six specific steps necessary for carrying out a successful literary ethnography on a vulnerable population. It focuses on the details surrounding the use of nonfiction literature to examine themes related to the verbal neglect and abuse of elder residents in nursing homes. 


\section{Step 1: Identifying the Problem and Selecting Literary Sources}

The first step in conducting a literary ethnography with Van de Poel-Knottnerus and Knottnerus' (1994) framework involves defining your research problem and determining a scope of sources. Since you will be analyzing literature, the problem should involve the possibility of studying human interaction displayed in written form. Studies in this tradition use written material to study themes in popular songs, religious symbols in hymns, trends in newspaper topics, and even the tone of newspaper editorials (for elaboration see Neuman, 1991). Sales' (1973) work focuses on comic strips and the presence and symbolic significance of protagonists, while Seider's (1974) research analyzes public speeches of U.S. corporate executives. More along the lines of a traditional literary ethnography, Griswold's (1981) work focuses on a random sample of novels from the late nineteenth and early twentieth centuries. It concerns how American novels reflect characteristics of the American experience.

This paper uses structural ritualization theory to focus on verbally neglectful and abusive RSPs in nursing homes. The topic of resident maltreatment in nursing homes is a precarious subject. To study it from a distance, the use of an unobtrusive method such as a literary ethnography is beneficial because characteristics of abuse might be incomprehensible just with a series of observations. A participant observer might witness a form of abuse and not even realize it. In addition, the observer might unethically participate in interaction that unintentionally harms residents. To avoid these dilemmas, it seems more appropriate to compile literature based on multiple observations to tap into abusive rituals in nursing homes.

When developing a scope of literary sources, you should obtain documents that focus on the environment under review. Clear boundaries for inclusion and exclusion of sources should exist. This involves having a specific idea of the topic. The sources should describe the experiences of actors in their social environment (Van de Poel-Knottnerus \& Knottnerus, 1994). In this research, the scope of literary sources includes books, book chapters, chapter sections, and articles concentrating on nursing home life. The researcher was aware of several sources at the onset of this project. The few known sources were not an adequate sample. To find additional sources, it was necessary to consult academicians familiar with literature pertaining to nursing homes. Upon their suggestions, additional sources emerged.

With a core of academic books and research monographs on nursing homes from the last 40 years, the researcher thoroughly examined the references of each source for more references. Then, the researcher scrutinized the references from those sources for even more references. Little academic information on nursing homes existed over 40 years ago because there were so few facilities. Care for the destitute old took place in what were known as poor farms until the middle of the 1900s, when federal programs such as Old Age Assistance and Medicare and Medicaid started fueling nursing home growth (Ulsperger \& Knottnerus, 2008). Regardless, several searches of library and Internet search engines also led to sources. This included searches using the keywords "nursing home" through the WorldCat, Proquest Direct, and JSTOR databases. With an intense search for all literature on nursing home life completed, the researcher ended up 
with 40 sources appropriate for analysis spanning the 1960s up until the modern era of nursing homes.

The sources included books and articles based on participant observation by sociologists and anthropologists. They also involved non-academic work, such as books written by family members with loved ones living in long-term care facilities and autobiographical accounts by people living in nursing homes. Some of the academic work examined general aspects of nursing homes, while some examined specific aspects such as television viewing habits. None of the biographic or autobiographic accounts focused on narrow characteristics, but they provided broad overviews of daily life in nursing homes.

\section{Step 2: Reading and Interpretation of the Documents}

The second step of Van de Poel-Knottnerus and Knottnerus' (1994) framework involves reading the literature. In this project, the researcher found it useful to use focused reading procedures. In other words, put yourself in a non-distracting environment in order to obtain a high level of concentration. Read some or all of the material, depending on your purpose, several times. Because the process involves interpretation, be familiar with the language typically used in the literature you are examining. This is critical. You will not be able to comprehend subtle nuances, informal phrases, and technical jargon without familiarizing yourself to the words used in everyday interaction in the environment between the people you are studying.

It might be beneficial to carry out a pre-study phase in which you research the social world you plan to analyze. You can do it without focusing on the area you plan to study with your literary ethnography. For example, if you plan to study hospice patients' attitudes toward death with a literary ethnography, before you perform your analysis, volunteer with a local hospice branch. Do not do so in order to collect information for your project, but merely to familiarize yourself with the terminology used. You might interview what observational researchers identify as gatekeepers and ask them questions that will develop your vocabulary of the environment under investigation. You might also read newspaper accounts or government documents in order to familiarize yourself with relevant vernacular (Hodder, 1994).

With this study, the researcher had work experience in long-term care that created a basic understanding of the language used in nursing homes. This included volunteering for nursing homes over a three-year period and an internship with an executive director of a nursing home lasting nearly six months. This helped considerably when reading the documents. In addition, earlier studies conducted by the researcher helped in comprehending nursing home language (for example see Paul \& Ulsperger, 2001). You should make sure that you are not the only researcher familiar with the terminology used in the setting you analyze. If others are working with you, ensure they are familiar with terminology as well. This will enhance the validity of your study in terms of any intercoder reliability issues (Hodder, 1994).

To disclose any biases, the work experiences and research mentioned above did influence the researcher's perceptions of nursing home life and motivated the current study. The idea existed that different forms of verbal neglect and abuse persist in nursing homes, but due to ethical constraints, the researcher did not feel comfortable in the work 
experiences encountered to ask employees and residents about neglect and abuse directly. Therefore, the intricacies of the forms of neglect and abuse reviewed in this project did not take form for the researcher until this analysis took place.

On a final note, it is important to mention that the research discussed in this paper is part of a larger qualitative document synthesis focusing on multiple forms of elder mistreatment in nursing homes. The larger study considered the influence of bureaucratization on the neglect and abuse of nursing home residents. Along with verbal components, it produced themes related to physical maltreatment and emotional neglect (see Ulsperger \& Knottnerus, 2007, 2008).

\section{Step 3: Identification of Textual Themes}

During and following the reading of documents, the third step in Van de PoelKnottnerus and Knottnerus' (1994) framework involves the identification of themes. These themes should focus on the experiences and features of the environment under review. The investigator should have an initial recognition of elements and patterns surfacing in the literature. The focus of thematic elements can involve a variety of things. In this research, over 100 themes emerged involving anything from general work routines such as nurse charting practices to family involvement and privacy issues. In some sources, authors describe meaningful relationships between residents and staff. Others note the importance of staff following rules. Many descriptions of maltreatment exist. Authors note the lack of cleanliness in specific domains of interaction such as living areas, recreational rooms, and kitchen areas. They also describe, among other things, the failure to deliver medicines at appropriate times, staff shoving food down residents' mouths, staff yelling at residents, staff ignoring pleas for assistance, and staff stealing. Themes involving resident abuse of staff also exist. The awareness of these themes allows the researcher to develop a crystallized understanding of interaction patterns. Reading through your documents is not a one-time event. You should re-read portions or all of your documents attempting to code new themes you are noticing while moving back and forth between documents to see if you are sensitive to even more elements or a reinterpretation of those you have already coded. For example, in this study, the researcher initially coded themes involving spoken interaction. Early on, it appeared that the research would end up focusing on verbal conflicts between residents and staff. However, after reading samples of nearly half of the sources, it was decided by everyone involved in the research process that themes revolving around staff talking to residents like children were becoming more noticeable. At that point, all the researchers involved went back to previously read materials seeking out examples of staff using "baby talk" as a form of verbal interaction. Even at that point, new themes that evaded the researchers before came to light and the back and forth reading process continued.

As a caveat, it is important to note that the biases built into the documents you review impact the themes that emerge. Authors' beliefs on the issues you research might reflect skewed realities of the actual topic you are studying. With this research, one of the first pieces of literature examined was Maudie: A Positive Nursing Home Experience (Metz, 1999). If the research used a majority of sources that emphasized the positive aspects of nursing home life, its credibility would suffer. So, seek balance in your research. Try to use a variety of documents, which appear pro, anti, and neutral in 
relation to the topic you explore. Make it a point to find multiple sources with different perspectives in order to create a holistic picture of the phenomenon you investigate. If this is not a possibility, disclose the lack of balance in your sources and reveal how it influenced your research.

Finally, take notes. Start keeping track of where examples of themes come from by author name, titles of documents, and page number. Your procedure for this can involve writing notes or typing them with the use of a computer, whatever your preference. In this project, everyone involved took written notes. One person lost a substantial number of notes early on in the process. It was then necessary to go back, read, and re-read the sources covered in those notes. Themes initially discovered were lost. They may have corresponded to the second version of notes, but then again they may not have. Later on in the project, it was decided that typed notes may be a better option with literary ethnographies. Typed notes would have allowed everyone involved the ability to easily backup files, and even search for themes within notes on themes, with a word processing program. Though this project did not implement it, it might also be possible to utilize computer software designed to find themes in documents to help researchers in their own reading and re-reading process.

\section{Step 4: Classification of Thematic Elements}

Based on the themes from the third step, the fourth step in Van de PoelKnottnerus and Knottnerus' (1994) literary ethnography process involves a specific classification system to organize all of the loosely existing themes from the previous stage. You simply focus your attention to a theme or themes present in the literature. Analysis indicates that early themes from the literary ethnography for this paper contain a wide variety of rituals related to social dynamics, bureaucratization, physical mistreatment, emotional maltreatment, and verbal neglect and abuse. These rituals concern, but are not limited to, relations between staff, between residents, staff and residents, staff and members from outside of the nursing home, and residents and people from outside of the nursing home. As discussed previously, this paper only reviews the classification of verbal neglect and abuse from residents to staff (see Ulsperger \& Knottnerus, 2007, 2008 for a review of others).

Keep in mind, once you make the decision on what to focus on, you should still be open to topics that emerge. Regardless, when determining the classification for themes, look for similar patterns in phrases, sentences, parts of a paragraph, or whole paragraphs. Concentrate on the degree that different authors express themes and the degree that the theme appears. You might find repeated comments on relationships. They might give a clear image of how interaction is coordinated. You might define the interaction as random, distant, or brief (Knottnerus \& Van de Poel-Knottnerus, 1999).

\section{Step 5: The Development of Analytic Constructs}

According to Van de Poel-Knottnerus and Knottnerus' (1994) methodology, the fifth step of a literary ethnography requires using analytic constructs. During this phase, it is also important to consider developing coding categories, defining recording units, and using a system of enumeration. 
Analytic constructs give a greater degree of structure to the analysis. The constructs should give better understanding to the loose themes generated in previous steps. The constructs should link to theoretical ideas external to the study. This makes for a comprehensive understanding of the subject matter and provides classification with a higher level of academic integrity (Van de Poel-Knottnerus \& Knottnerus, 1994).

The theoretical link can come from a variety of disciplines. According to Van de Poel-Knottnerus and Knottnerus (2002), the source of the analytical concepts is secondary to the goal of strengthening your interpretation. Specifically, this means you should not limit the ideas or theoretical perspectives you apply to your study to those existing exclusively in your field. If you are in the social sciences, branch out and entertain the use of perspectives from sociology, anthropology, psychology, law, linguistics, geography, or political science.

For themes on abuse in this study, the researcher used a previously developed definition of elder maltreatment. Pillemer (1988) defines elder maltreatment as any "deviation from expected standards for high-quality care” (p. 228) including actions such as verbal aggression and abuse. When applying this definition to the themes interpreted in this research, the researcher defined categories of verbal neglect and abuse as involving aspects of infantilization, spoken aggression, and ignoring. As such, this work defines infantilization as condescending staff vocalizations that reduce the status of a resident to that of a young child. It defines spoken aggression as author references to the hostile launching of vocal attacks by staff directed against a resident. Finally, it defines ignoring as situations where nursing home employees refuse to take notice of verbal communication initiated by residents. This includes ignoring requests for personal and medical assistance.

As with the three branches of verbal neglect and abuse mentioned, categories should be exclusive. The overall value of your literary ethnography coding depends on the formulation of specific content categories and consistent definitions for placing units into categories (Singleton \& Straits, 2005). With that in mind, intercoder reliability is important to discuss again. Everyone involved in the research process is going to go back and read each piece of literature at this point. While doing so, they should count instances of thematic representation and mark quality examples in case they want to use them as thick descriptions when writing up the research. Make sure everyone involved in the coding process uses the same definitions. In addition, if possible have every researcher involved code the same literature. Once that process is complete, compare coding. Then, debate instances that individuals do not agree on until a consensus for category placement emerges. If a large body of literature exists, it might be a necessity to break sources up between researchers. If this is the case, be sure and have each member of the research team hold questionable instances to the side so the entire team can discuss category placement at a later point.

In terms of intercoder reliability, you should also have clear boundaries for your recording units. The recording unit is the element of the document described by content categories. This could be a single word, symbol, sentence, paragraph, or other grammatical unit. It could also be the entire document. As mentioned, Sales' (1973) work uses character descriptions. Griswold's (1981) research uses character, plot, and entire novels. Though researchers can code smaller units more reliably then larger ones, smaller units may not be sufficient to extract latent meanings. Numerous small units coded from 
a large collection of documents may be too much for a researcher to manage (Berg, 2007). However, regardless of your recording unit, try to keep possible context problems in the back of your mind. Consider the work of Namenwirth (1969). It describes the editorial orientation of British elite and mass newspapers. He showed that decades ago British elite newspapers, as opposed to mass newspapers, had an overwhelming concern with European affairs and not the Cold War. It indicates that the presence of terms such as Soviet and American indicate concern with the Cold War. When considering context, there is a problem with this technique. The mere presence of such words does not mean that an article takes a pro- or anti-American position. To take this stance, you have to think about the larger context unit (Singleton \& Straits, 2005).

This study uses paragraphs and larger grammatical recording units. Larger units include portions of book chapters as themes. This involves a focus on themes related to the previously described categories. In fact, each theme actually represented the occurrence of a RSP of verbal neglect and abuse. Larger recording units are necessary when the focus on descriptions and meanings is important - not just the appearance of words or phrases associated with verbal neglect and abuse.

As with a basic content analysis, it is necessary in a literary ethnography to define a system of enumeration. This involves at least a simple quantification of the information. Careful measurement is important. After all, the researcher is turning general communication into precise elements of inquiry (Neuman, 1991). Systems of enumeration involve time-space measures, appearance, frequency, and intensity (Singleton \& Straits, 2005).

Time-space measures involve attention given to a topic. Early content analysts of newspapers measured the inches of the columns covering topics. Appearance, also known as direction, involves confirming the presence of a category in a recording unit. It focuses on the position that it appears to take (Singleton \& Straits, 2005). For example, Sales' (1973) work classifies characters in comic strips as powerful or not. Griswold's (1981) research measures whether main characters are male or female.

Frequency is the most common system of enumeration. It involves keeping track of the times a category occurs (Singleton \& Straits, 2005). For example, in an analysis of Democratic and Republican Party platforms, Weber's (1990) research calculates the proportion of words in a category of wealth. This involves counting the presence of words such as capital, inflation, and unemployment. Intensity focuses on the values and attitudes present in an analysis of documents. Instead of focusing on the number of times money appears in a document, a researcher would focus on the author's passion in discussing the issue of money (Singleton \& Straits).

This study uses frequency and intensity as systems of enumeration. It counts the number of times themes related to categories of verbal neglect and abuse appear in the literature. The research does not use these numbers for statistical analysis. It only uses them for descriptive purposes (for more on this issue see Berg, 2007). Regardless, this literary ethnography was open to emerging themes throughout the coding process. An open category of "other" for themes not initially discovered supplements the findings while remaining exclusive to the three defined categories.

The use of frequencies implies that all elements categorized carry equal weight. However, this is not always the case. It is possible that the content of a theme in one situation emphasizes an issue to a higher degree when compared to another. In these 
situations, this work uses excerpts to highlight the power, or intensity, behind comments in recording units.

\section{Step 6: Contextual Confirmation}

The final step in a literary ethnography is contextual confirmation. Here, you reread all or portions of your literary sources a final time. This helps you decide if your established themes correctly relate to the final coding scheme. According to Van de PoelKnottnerus and Knottnerus (1994), you are checking to make sure that the final idea of the environment under review corresponds with the original narratives read. In this study, the researcher and other person helping with data analysis re-read all of or portions of the documents used depending on the source. Each read shorter documents and research articles entirely and chapters of books to confirm that the categories and constructs created accurately represent the major themes found earlier. It is important to remain open to other themes that emerge so you can, as with this study, place them in an "other" category for future analysis.

You should not limit your contextual confirmation to a final re-read. In this study, the lead researcher discussed findings with other people interested in nursing home issues and also family members of people living in nursing homes. When you discuss your findings with other people familiar with the environment you study, they have the ability to let you know if your findings "gel" with their perceptions. If they do, you establish an even higher level of trustworthiness for your research (Hodder, 1994).

\section{Findings}

In this research, RSPs of verbal neglect and abuse include themes related to infantilization, spoken aggression, and ignoring. Table 1 shows the sources reference RSPs of verbal neglect and abuse 328 times.

Table 1

Frequencies for Verbal Neglect and Abuse Rituals

\begin{tabular}{lcc}
\hline Category & Number & $\%$ \\
\hline Infantilization & 144 & 43.9 \\
Spoken Aggression & 96 & 29.3 \\
Ignoring & 86 & 26.2 \\
Other & $\mathbf{2}$ & $\mathbf{0 . 6}$ \\
\hline Total & $\mathbf{3 2 8}$ & $\mathbf{1 0 0 . 0}$
\end{tabular}




\section{Infantilization}

RSPs of infantilization involve condescending staff vocalizations that reduce the status of a resident to that of a young child. People in nursing circles use the term and various studies exist that examine infantilization and its impact on the aged (see Gresham, 2007). Table 1 shows the sources reference this category 144 (43.9\%) times. In terms of salience, several sources show the intensity of this category. In one, KayserJones (1981) explains:

At Pacific Manor there were innumerable incidents of staff treating the residents like children. Authoritarian scoldings of the aged by staff were common. For example, one day a nurse aide walked into the lounge and, seeing a puddle of water on the floor, asked loudly, "Who wet the floor?" Pointing her finger at one woman, she inquired in an accusing voice, "Did you wet the floor?" Very embarrassed at being singled out as the culprit, the patient replied, “Why, no it wasn’t me.” (p. 39)

Staff members do not always intend malice with their comments. In one source, Diamond (1992) points out:

In this instance [a staff member] was using the term "baby" to ridicule the rule... that bibs had to be tied onto each resident for each meal. "Baby" was often used, and in more than one way. In some contexts it was used to create fictive family roles. Dorothy Tomason put her arm around Joanne Macon when she cried. "C'mere, my baby, now what's the trouble...” (p. 138)

Extending this idea, Savishinsky (1991) points out that in the facility he observed there was an "infantilizing habit of addressing residents with unearned terms of endearment: 'honey,' 'love,' 'sweetie,' and 'dear' were patronizing to the ear” (p. 75). This paper did not consider separating sources written about southern nursing homes from others, but it is important to note that in some areas of the southern U.S. people use infantile terms such as "baby" when engaging in typical interactions with others regardless of age. One could argue that most people in the South do not use these phrases for people to interpret them literally. However, staff cannot control how others interpret their language, assuming that all residents in southern nursing homes are from the South themselves. Moreover, when staff freely infantilize language without malicious intent, it has the potential to do the most damage, especially when directed toward older individuals already susceptible to poor self-image due to factors of dependency and functional impairment (see Whitmer \& Whitbourne, 1997).

Interestingly, residents resist these RSPs when they are condescending. Diamond (1992) points out that the use of terms like "baby" often create conflict between staff members and residents as illustrated with the following example:

Bedridden Frances Wasserman protested, “Just cause I have to lay here in this gown doesn't mean I'm a baby.” The same protests came up at 
mealtime in the same tone, in part, because of bibs but also for the reason expressed by Mrs. Herman, who was blind. "You know, I was a field nurse, too. I'm no baby just because someone has to help me eat.” (p. 138)

It is possible that staff members are trying to negotiate their relationships with residents when they infantilize. In doing so, they use cognitive frameworks that guide other relationships where they act as caregivers. Diamond (1992) points out, often these are parent-child relationships. As an unintended consequence, residents interpret the use of this cognitive framework as degrading. Other, possibly unintended, RSPs relate to infantilization in nursing homes. Kayser-Jones (1981) points out one facility she was familiar with saved on expenses by only showing movies donated from a nearby child daycare.

\section{Spoken Aggression}

RSPs of spoken aggression involve author references to the hostile launching of vocal attacks by staff directed against a resident. Table 1 shows $96(29.3 \%)$ references in the sources. References to this category rank high in terms of frequency, but are not very salient. Some of the sources indicated that employees use spoken aggression to deter residents from bothering staff. Howsden (1981) explains:

A typical encounter includes a complaint of a headache, stomachache or another patient who has caused them distress. The patient is not ignored, but merely put off with the typical response, "Oh, go sit down and you will feel better," or "You... go find something to do like feeding the cat," or "Go help Mrs. C. with her chair." The tactic is one of diversion which if unsuccessful is followed by threats, such as "If you don't leave me alone, I’ll send you to your room.” (p. 76)

In some sources, administrators favor floor staff ritualistically using spoken aggression. They believed it helped to speed along work tasks. In one source, administrative employees praised a nurse that humiliated and verbally assaulted patients. Few similar examples with such a strong tone exist in the literature. Regardless, her verbal attacks made residents do what upper level staff thought they should. Foner (1994) explains:

When [a resident] complained that she could not eat because her foot hurt, Ms. James screamed, "Shut up you and eat you. Eat. You think I have all day..." And she turned to another woman, "You're such a nasty pig. You hear me, drink..." When a resident Ms. James had put on the toilet complained, she barked, “Sit there. Just sit. I don't care what hurts, just sit there..." As the LPN passed, Ms. James loudly commented so that the [other] residents could hear: "Two dingbats I got here. One has shit coming out of her ass and the other one says her back hurts..." Ms. James humiliated and verbally abused patients out in the open: in front of nurses, 
administrators, doctors, and visitors. Yet she received the best evaluation on the floor and had privileges denied other aides. (p. 61)

\section{Ignoring}

RSPs of ignoring concern situations where nursing home employees refuse to take notice of verbal communication initiated by residents (for more on this process see Goffman, 1967). This includes ignoring requests for personal and medical assistance. Here, residents make personal or medical requests and employees do not acknowledge them. Table 1 indicates 86 (26.2\%) references to RSPs of ignoring. In terms of salience, intense examples of ignoring exist. In one source, Paterniti (2000) explains:

Staff meet residents, whom they identify as disruptive or incompetent, at the convenience of their own work schedule. By doing so, they sometimes avoid residents whom they believe will reduce control over the work shift. This formula for interaction, however, may have detrimental consequences for "difficult" residents. Hazel Kleweski - a 325-pound, bed-bound resident in her early sixties - often had trouble with her meals, pushing her nurse's call button to alert staff of her digestive complications. Because Hazel rang her call button at each meal, her call light often went unanswered by staff who were trying to assist resident "feeders" during the institutionally designated mealtime. (p. 106)

As one resident told Gubrium (1993), "You ask them to do something and they ignore you like dirty shit” (p. 144).

In another source, Gubrium (1975) explains, that residents have various resources to influence work patterns of lower staff. They can be uncooperative or complain. Nurses and aides on the floor know the residents that are uncooperative or complain the most. They see a lack of cooperation or complaining as disruptions of their work routine. Ignoring these residents sends a symbolic, punitive message to others to not disrupt organizational tasks or they would receive similar treatment. Residents comply with staff work routines fearing the stigma of being a troublemaker.

Vaughan (1999) explains that routine practices in organizations can have unintended consequences. This concept is highly relevant to aspects of employees ignoring residents in nursing homes. Ignoring a resident's plea for help can be risky and have horrifying results. In one source, Paterniti (2000) explains:

This afternoon, I talked with a staff member over lunch about some of the residents at Merimore who had died during my days off. Jessica said, "It was during lunch, ya know, when we're reeeaal busy. As usual, we were still passing trays, and Hazel put on her [nurse call] light. Naturally, Michele [Hazel's usual aide] just ignored it.” Jessica noted with a certain matter-of-factness: anyone who had any knowledge of Hazel, her deficiencies, and the work routine would have, of course, followed the same course of action. She continued, "When Michele went in [to Hazel's 
room] to pick up Hazel's tray, she [Hazel] didn't respond. She wasn't breathing (the aide swallowed). Hazel was dead.” (p. 106)

\section{Other}

In the "other" category, only two references that did not fit into the previous categories appear. They concern making loud noises in the halls when residents are trying to sleep (see Tisdale, 1987). With so few references, a table for frequencies to examine repetitiveness and a discussion of salience is not of concern in this study.

\section{Conclusion}

This study shows that using literary ethnography methods yields valuable data when studying vulnerable populations. It indicates that rituals of verbal abuse and neglect in nursing homes are more likely to involve infantilization. It is possible that RSPs tied to infantilization relate to cost-cutting measures. For example, one source indicates that instead of buying movies for residents to watch, one home used movies donated by a local child daycare. Vocal patterns present in sources imply that staff members in most institutions talk to residents as if they were children. When considering frequency, this study indicates that spoken aggression is a likely form of verbal abuse in nursing homes as well, but there are not many examples in the sources indicating the salience of this category. The examples that do exist reveal that staff members use threats to get residents to comply with the institutional order. These threats send a symbolic message that organizational tasks are the primary concern, not the resident. Administrators sometimes reward lower employees who ritualistically use spoken aggression. Ironically, the least referenced category, ignoring, was the most disturbing. Some staff members make a ritual practice out of ignoring those who disrupt work schedules. In doing so, they avoid situations they should not. From Vaughan's (1999) perspective, we can identify this as organizational deviance. Staff members deviate from the formal goal of the organization, caring for residents, and opt to focus on bureaucratic goals instead. It seems that in nursing homes the completion of organizational tasks is more important than providing quality care, which oddly many of the organizational tasks are supposed to facilitate. In turn, unanticipated consequences, even deaths, occur.

Future research on abuse with vulnerable nursing home populations should maximize the benefits of literary ethnography techniques, possibly combining them with traditional quantitative methods. In addition, future research should not be limited to articles and books. Though this study did not search for or analyze fiction literature focusing on accounts of nursing home life, they could exist and be studied. Future research might also involve other types of nonfiction documents not used in this research. This includes communications from sources such as testimonies from government investigations or publicly available court records.

This study focuses on nursing homes, but the use of literature to study social worlds is not rare. As previously noted, people have been doing it for years (Hodder, 1994). In the case of this research, you can see how using a literary ethnography as a qualitative document synthesis tool is advantageous. It gives order to the study of documents. It provides systematic steps for studying documents. It even has the potential 
to accent other forms of research if used to develop a familiarity with a topic before entering a more intense stage of research. Even when just using it as an exploratory tool, keep in mind that its steps have the ability to increase the trustworthiness of a research project (Van de Poel-Knottnerus \& Knottnerus, 1994).

As a form of content analysis, it also is an effective unobtrusive method. The researcher does not need to interview anyone about controversial behaviors. No one fills out lengthy questionnaires. No one has to enter the high-pressure environment of a laboratory. Though its focus on reading and re-reading can be monotonous at times, it can be cost effective as well (Berg, 2007). Inevitably, if you use a literary ethnography as a form of content analysis, you will encounter critiques based on quantitative ideologies. Specifically, you will have to confront issues on validity and reliability.

It is possible to argue that a literary ethnography has a high level of face validity when it, as in the case of this study, uses documents that provide nonfiction, first-hand accounts. However, you must keep in mind that these first hand accounts may lower face validity if authors wrote the documents you are analyzing with a biased opinion. As noted earlier, biased authors do not provide objective descriptions of social environments, so use as many sources as possible (Bailey, 1978; Denzin \& Lincoln, 2008). Another critique involves possible "reality" lags between when authors observe and later write materials. The survival rate of a document is also important to consider. Certain older documents on a population or environment under review might outlive others due to hyperbolic, entertaining, but exaggerated versions of the topic under review that led to their increased popularity. In addition, historical circumstances influencing the content of documents from different times might produce an inconsistent picture (Berg, 2007). As in the case of this study, the documents used come from a wide time range - the 1960s until the modern nursing home era. Should you treat sources from different decades equally, or might the documents from recent years create a very different version of reality than those written a few decades ago?

As a form of content analysis, a literary ethnography can concern two types of reliability - instrument and analyst. Instrument reliability involves comparing documents at one or more points in time. As previously alluded, this is often low because of selective survival of documents. Analyst reliability involves cross checking the work of different researchers from the same period. This can be high when several documents from the same time are available. Regardless, the main reliability issue in a literary ethnography concerns category definitions. As this work details, you must construct categories and decide on recording units, context units, and a system of enumeration. It will be a subjective process, but with a focus on the use of widely used analytic constructs and intercoder reliability measures, you can produce a legitimate piece of research (Singleton \& Straits, 2005).

\section{References}

Allport, G. (1942). The use of personal documents in psychological science (Bulletin 49). New York: Social Science Research Council.

Bailey, K. D. (1978). Methods of social research. New York: Free Press.

Berg, B. L. (2007). Qualitative research methods for the social sciences. Boston: Pearson. 
DeFrancis, M. (2002). U. S. elder care is in a fragile state. Population Today, 30, 1-3.

Denzin, N. K. (1978). Sociological methods. New York: McGraw-Hill.

Denzin, N. K., \& Lincoln, Y. S. (Eds.). (2008). Strategies of qualitative inquiry. Thousand Oaks, CA: Sage.

Diamond, T. (1992). Making gray gold: Narratives of nursing home care. Chicago: University of Chicago Press.

Doyle, L. H. (2003). Synthesis through meta-ethnography: Paradoxes, enhancements, and possibilities. Qualitative Research, 3, 321-344.

Flaskerud, J., \& Winslow, B. J. (1998). Conceptualizing vulnerable populations: Healthrelated research. Nursing Research, 47(2), 69-78.

Foner, N. (1994). The caregiving dilemma: Work in an American nursing home. Berkeley: University of California Press.

Glassner, B., \& Corzine, J. (1982). Library research as fieldwork: A strategy for qualitative content analysis. Sociology and Social Research, 66, 305-319.

Goffman, E. (1967). Interaction ritual. New York: Pantheon.

Gresham, M. L. (2007). The infantilization of the elderly: A developing concept. Nursing Forum, 15(2), 195-210.

Griswold, W. (1981). American character and the American novel: An expansion of reflection theory in the sociology of literature. American Journal of Sociology, 86, 740-765.

Guan, J., \& Knottnerus, J. D. (1999). A structural ritualization analysis of the process of acculturation and marginalization of Chinese Americans. Humboldt Journal of Social Relations, 25, 43-95.

Gubrium, J. F. (1975). Living and dying at Murray Manor. New York: St James Press.

Gubrium, J. F. (1993). Speaking of life: Horizons of meaning for nursing home residents. Hawthorne, NY: Aldine de Gruyter.

Hodder, I. (1994). The interpretation of documents and material culture. In N. K. Denzin \& Y. S. Lincoln (Eds.), Handbook of qualitative research (pp. 393-402). Thousand Oaks, CA: Sage.

Hodges, S., \& Ulsperger, J. S. (2005). Presentations of the paranormal: The impression management strategies and professionalization tactics of psychics and spirit mediums. Free Inquiry in Creative Sociology, 33(1), 35-50.

Howsden, J. L. (1981). Work and the helpless self: The social organization of a nursing home. Washington, DC: University Press of America.

Kayser-Jones, J. S. (1981). Old, alone, and neglected: Care of the aged in Scotland and the United States. Berkeley: University of California Press.

King, N. (1998). Template analysis. In G. Symon \& C. Cassell (Eds.), Qualitative methods and analysis in organizational research (pp. 118-134). London: Sage.

Knottnerus, J. D. (1997). The theory of structural ritualization. In B. Markovsky, M. J. Lovaglia, \& L. Troyer (Eds.), Advances in group processes (pp. 257-279). Greenwich, CT: JAI Press.

Knottnerus, J. D. (1999). Status structures and ritualized relations in the slave plantation system. In T. J. Durant Jr. \& J. D. Knottnerus (Eds.), Plantation society and race relations (pp. 139-147). Westport, CT: Praeger.

Knottnerus, J. D., \& Berry, P. (2002). Spartan society: Structural ritualization in an ancient social system. Humboldt Journal of Social Relations, 27, 1-41. 
Knottnerus, J. D., Ulsperger, J. S., Cummins, S., \& Osteen, E. (2006). Exposing Enron: Media representations of ritualized deviance in corporate culture. Crime, Media, Culture, 2(2), 177-195.

Knottnerus, J. D., \& Van de Poel-Knottnerus, F. (1999). The social worlds of male and female children in the nineteenth-century French educational system: Youth, rituals, and elites. Lewiston, NY: Edwin Mellen Press.

Manning, P., \& Cullum-Swan, B. (1994). Narrative, content, and semiotic analysis. In N. K. Denzin \& Y. S. Lincoln (Eds.), Handbook of qualitative research (pp. 463477). Thousand Oaks, CA: Sage.

Marshall, C., \& Rossman, G. B. (1995). Designing qualitative research (2nd ed.). Thousand Oaks, CA: Sage.

Metz, R. L. (1999). Maudie: A positive nursing home experience. Hanover, MA: Christopher.

Namenwirth, J. Z. (1969). Marks of distinction: An analysis of British mass and prestige newspaper editorials. American Journal of Sociology, 74, 343-360.

Neuman, W. L. (1991). Social research methods: Qualitative and quantitative approaches. Boston: Allyn \& Bacon.

Noblit, G. W., \& Hare, R. D. (1988). Meta-ethnography: Synthesizing qualitative studies. Newbury Park, CA: Sage.

Paterniti, D. A. (2000). The micropolitics of identity in adverse circumstance: A study of identity making in a total institution. Journal of Contemporary Ethnography, 29, 93-119.

Paul, J., \& Ulsperger, J. S. (2001). Disaster preparation and long-term care: An evaluation of tornado safety in Oklahoma nursing homes. Southwest Journal on Aging, 17(1/2), 41-46.

Pear, R. (2002, February 18). 9 out of 10 nursing homes lack adequate staff, study finds. New York Times, pp. 11.

Pillemer, K. (1988). Maltreatment of patients in nursing homes: Overview and research agenda. Journal of Health and Social Behavior, 29, 227-238.

Sales, S. M. (1973). Threat as a factor in authoritarianism: An analysis of archival data. Journal of Personality and Social Psychology, 28, 44-57.

Savishinsky, J. S. (1991). The ends of time: Life and work in a nursing home. New York: Bergin \& Garvey.

Seider, M. S. (1974). American big business ideology: A content analysis of executive speeches. American Sociological Review, 39, 802-815.

Sell, J., Knottnerus, J. D., Ellison, C., \& Mundt, H. (2000). Reproducing social structure in task groups: The role of structural ritualization. Social Forces, 79, 453-475.

Singleton, R., \& Straits, B. C. (2005). Approaches to social research. New York: Oxford University Press.

Statistical Abstract of the United States. (2007).Tables 11, 161, 172. Washington DC: Bureau of the Census.

Thomas, W. I., \& Znaniecki, F. (1918). The Polish peasant in Europe and America. Boston: Badger.

Tisdale, S. (1987). Harvest moon, portrait of a nursing home. New York: H. Holt. 
Ulsperger, J. S., \& Knottnerus, J. D. (2007). Long-term care workers and bureaucracy: The occupational ritualization of maltreatment in nursing homes and recommended policies. Journal of Applied Social Science, 1(1), 52-70.

Ulsperger, J. S., \& Knottnerus, J. D. (2008). The social dynamics of elder care: Rituals of bureaucracy and physical neglect in nursing homes. Sociological Spectrum, 28, 357-388.

Van de Poel-Knottnerus, F., \& Knottnerus, J. D. (1994). Social life through literature: A suggested strategy for conducting a literary ethnography. Sociological Focus, 27, 67-80.

Van de Poel-Knottnerus, F., \& Knottnerus, J. D. (2002). Literary narratives on the nineteenth and early twentieth-century French elite educational system. Lewiston, NY: Edwin Mellen Press.

Varner, M. K., \& Knottnerus, J. D. (2002). Civility, rituals, and exclusion: The emergence of American golf during the late nineteenth and early twentiethcenturies. Sociological Inquiry, 72, 426-441.

Vaughan, D. (1999). The dark side of organizations: Mistakes, misconduct, and disaster. Annual Review of Sociology, 25, 271-305.

Weber, R. P. (1990). Basic content analysis. Newbury Park, CA: Sage.

White, H. (1986). Tropics of discourse: Essays in cultural criticism. Baltimore: Johns Hopkins University Press.

Whitmer, R. A., \& Whitbourne, S. K. (1997). Evaluation of infantilizing speech in a rehabilitation setting: Relation to age. International Journal of Aging and Human Development, 44(2), 129-136.

\section{Author Note}

Jason S. Ulsperger is assistant professor of sociology at Arkansas Tech University. He received his master's degree from Arkansas State University and Ph.D. from Oklahoma State University. He teaches courses in sociology, criminal justice, and gerontology. His current research focuses on occupational rituals that promote deviant and criminal behavior in organizations. His recent publications appear in Crime, Media, Culture: An International Journal, Applied Social Science, and Sociological Spectrum.

The author can be contacted at Witherspoon Hall 355, Arkansas Tech University, Russellville, AR 72801; Telephone: (479) 968-0464; E-mail: julsperger@atu.edu

Copyright 2009: Jason S. Ulsperger and Nova Southeastern University

\section{Article Citation}

Ulsperger, J. (2009). Using literary ethnography as a form of qualitative document synthesis to explore the maltreatment of vulnerable populations: An examination of verbal neglect and abuse in nursing homes. The Qualitative Report, 14(4), 807-824. Retrieved from http://www.nova.edu/ssss/QR/QR14-4/ulsperger.pdf 